\title{
Quantitative evaluation of reactive nitrogen emissions with urbanization: a case study in Beijing megacity, China
}

\author{
Chaofan Xian ${ }^{1,2} \cdot$ Zhiyun Ouyang ${ }^{1} \cdot$ Fei Lu ${ }^{1} \cdot \operatorname{Yang} \mathrm{Xiao}^{1} \cdot \operatorname{Yanmin} \mathrm{Li}^{3}$
}

Received: 21 September 2015 / Accepted: 23 May 2016/Published online: 30 May 2016

(C) Springer-Verlag Berlin Heidelberg 2016

\begin{abstract}
The rapid increase in anthropogenic nitrogen $(\mathrm{N})$ load in urbanized environment threatens urban sustainability. In this study, we estimated the amount of reactive $\mathrm{N}(\mathrm{Nr})$ as an index of $\mathrm{N}$ pollution potential caused by human activities, using the megacity of Beijing as a case study. We investigated the temporal changes in $\mathrm{Nr}$ emissions in the environment from 2000 to 2012 using a multidisciplinary approach with quantitative evaluation. The $\mathrm{Nr}$ emissions presented slightly increasing during study period, and the annual emission was $0.19 \mathrm{Tg}$ $\mathrm{N}$, mainly resulting from fuel combustion. Nevertheless, the $\mathrm{Nr}$ output intensity resulting from inhabitants' livelihoods and material production had weakened over the study period. The evaluation results showed that the environmental measures to remove $\mathrm{Nr}$ in Beijing were efficient in most years, suggesting that progress in mitigating the growth of the $\mathrm{Nr}$ load in this urban environment was significant. Further measures based on $\mathrm{N}$ offset are suggested that could help alleviate the environmental pressure resulting from anthropogenic $\mathrm{Nr}$ emissions. These could provide theoretical support for the sustainable development of megacities.
\end{abstract}

Keywords Urbanization - Reactive N · Waste treatment . Data envelopment analysis $\cdot \mathrm{N}$ offset $\cdot$ Beijing

\section{Responsible editor: Gerhard Lammel}

Zhiyun Ouyang

zyouyang@rcees.ac.cn

1 State Key Laboratory of Urban and Regional Ecology, Research Center for Eco-Environmental Sciences, Chinese Academy of Sciences, Beijing 100085, China

2 University of Chinese Academy of Sciences, Beijing 100049, China

3 School of Geographical Sciences, Southwest University, Chongqing 400715, China
Urbanization is the global multidimensional process of human development and material consumption concentrated in urban areas; the urban ecosystem is an anthropogenic heterotrophic ecosystem that strongly relies on external material consumption, especially nutrients. As an essential element for life, nitrogen $(\mathrm{N})$ is consumed to support the acceleration of city development, suggesting that urbanization has a major impact on the natural $\mathrm{N}$ cycle (Lin et al. 2014; Liu et al. 2015). Thus, it is important to understand the adverse effects of $\mathrm{N}$ cycle disturbance on the environment during urbanization. The improvement in inhabitants' livelihoods and industrialization are the main factors driving the increased demand for $\mathrm{N}$ consumption, resulting in increased $\mathrm{N}$ emissions to the environment (Liu et al. 2015). Especially in the megacity ecosystem, where the urban core strongly affects its periphery areas including suburban and rural regions (Gu et al. 2009), the magnitude of this increase is larger than that driven by natural processing (Duh et al. 2008). For instances, in terms of domestic food consumption, the $\mathrm{N}$ embedded in proteins from food for human consumption accounts for approximately $20 \%$ of the total $\mathrm{N}$ input for food production (Galloway and Cowling 2002). This means that the majority of $\mathrm{N}$ is released to the environment before the food is consumed. This increase in the emission of superfluous $\mathrm{N}$ resulting from anthropogenic activities in urban environments might be partly responsible for regional eutrophication, acid rain, air pollution, global warming, and photochemical smog, as well as a general degradation of biodiversity (Galloway et al. 2008). Therefore, urban $\mathrm{N}$ consumption is thought to be the one of the main sources of territorial $\mathrm{N}$ pollution.

There is an attempt in urban areas to recover ecosystem services, such as waste treatment, by using discharged waste in the waste treatment system (Lin et al. 2014). However, the discharge paths of $\mathrm{N}$ fluxes from waste treatment facilities in urban ecosystems differ from those in natural ecosystems. 
Compared with direct urban $\mathrm{N}$ emissions, such as vehicle emissions, indirect $\mathrm{N}$ emissions from waste treatment, including the treatment of gaseous pollutants, sewage, and municipal garbage, are often unknown to the general public, who are unaware of this source of $\mathrm{N}$ pollution. In China, the number of urban areas designated as cities increased from 132 in early 1949 to 657 in 2012 with urban populations growing from 10.60 to $52.57 \%$, highlighting the increasing role of cites as sources of N, even after waste treatment (Gu et al. 2013a). Liu et al. (2015) found that the amount of $\mathrm{N}$ from industry and wastewater treatment discharged into water bodies in Shanghai city increased significantly from $60.1 \times 10^{3} \mathrm{t} \mathrm{N}$ in 1980 to $116.2 \times 10^{3} \mathrm{t} \mathrm{N}$ in 2000 , despite the spread of sewage treatment systems and improvements in treatment technology. Although their study focused on the effects of $\mathrm{N}$ load on the water environment, they suggested that the analysis of $\mathrm{N}$ load discharged to the whole of the urban environment, including air, soil, and water, should be studied to provide more understanding of $\mathrm{N}$ fluxes in urban socio-ecological systems undergoing rapid growth. Therefore, in this study, we focused on $\mathrm{N}$ emissions to the air, soil, and water in an urban environment (Lin et al. 2014).

As a "super city," that is, one where the population is over ten million more than before the start of the twenty-first century, Beijing is now facing many environmental problems because of rapid urbanization within its boundaries. To feed the increasing urban population, megacities need to consume more nutrients including N. However, the interactions of social, economic, and ecological drivers of urban ecosystem structure and function are particular challenges in the $\mathrm{N}$ metabolism analysis of Beijing during urbanization. In view of the dynamic variation of $\mathrm{N}$ flows arising from human activities in urban regions, it is important to evaluate the temporal changes in anthropogenic $\mathrm{N}$ emissions in densely populated cities, such as Beijing (Han et al. 2011). The specific objectives of this study were to (i) provide preliminary quantitative estimates of annual anthropogenic $\mathrm{N}$ emissions of Beijing and analyze their temporal variations from 2000 to 2012, (ii) evaluate the efficiency of urban pollutant removal during the study period using an economic input-output model, and (iii) construct a conceptual framework based on $\mathrm{N}$ offset to provide theoretical supports for the government to mitigate $\mathrm{N}$ pollutions resulting from urbanization.

\section{Study area}

Beijing, the capital city of China, is at the northern tip of the North China Plain (Fig. 1). By 2012, the Beijing metropolitan region was $16.411 \times 10^{3} \mathrm{~km}^{2}$, with a residential population of around 21 million. As one of the megacities with the highest population density worldwide, the rapid urbanization of Beijing has resulted in environmental problems related to the enrichment of $\mathrm{N}$ load such as air pollution, eutrophication, and white pollution (Sun et al. 2008). Although Beijing city has more advanced wastewater and municipal garbage treatment facilities compared with many of the cities in China and, thus, higher disposal rates of 83 and $99.1 \%$, respectively (Beijing Statistics Bureau 2013), the magnitude of N loss after waste treatments remains high.

\section{Estimating Nr emissions}

\section{Methodology}

To integrate the anthropogenic $\mathrm{N}$ flows in Beijing, we took the Beijing metropolitan regions, including urban and suburban areas, as the system boundary for calculations, enabling us to focus on anthropogenic $\mathrm{N}$ emissions within this region. The forms of consumed $\mathrm{N}$ resulting in $\mathrm{Nr}$ (Galloway et al. 2008) included all activated $\mathrm{N}$ atoms contained in organic $\mathrm{N}$, ammonium, $\mathrm{NO}_{\mathrm{x}}, \mathrm{N}_{2} \mathrm{O}$, and nitrate. The amount of $\mathrm{Nr}$ emissions was estimated by accounting for anthropogenic $\mathrm{Nr}$ outputs in four units based on the sources of terminal emissions: fuel combustion, wastewater treatment, municipal garbage disposal, agricultural livestock farming, and fertilizer application (Fig. 2). The emission inventories mainly included fuel combustion caused by residents and commodity production in city sectors (agriculture, industry, and commerce) and indirect release through agricultural ammonia volatilization, as well as the $\mathrm{N}$ losing by waste treatment including emissions from incineration, denitrifying volatilization from treatment processes, discharging of treated and untreated sewage, leaching from landfill, and discarding of untreated garbage and sludge. Waste recycling and water reuse were not considered as $\mathrm{Nr}$ outputs from the region because they reflect a redistribution of $\mathrm{Nr}$ within the urban ecosystem, rather than being discharged to the environment. Besides, it is still hard to clearly quantify the highly uncertain emissions such as ammonia emissions from combustion sources especially in China (Reis et al. 2009), and these ammonia emissions would not be included in estimation in this study.

We obtained environmental and economic data mainly from yearbooks published by Beijing Municipal Bureau of Statistics and National Bureau of Statistics of China (2000-2013a, b, c), which, in recent years, have supplied the best available data for the calculation of anthropogenic $\mathrm{N}$ fluxes in China (Gu et al. 2009). In this study, the official statistical data from 2000 to 2012 were used, a time period in which an improved system of up-to-date data collection was in place. Uncertainties of estimation were based on data from the yearbooks, but because they used the same system for the statistic, the uncertainties were assumed to fall in the range of $\pm 5 \%$ (Gu et al. 2012a). The coefficients used for the calculations of $\mathrm{N}$ fluxes were derived from field surveys and peer studies. 


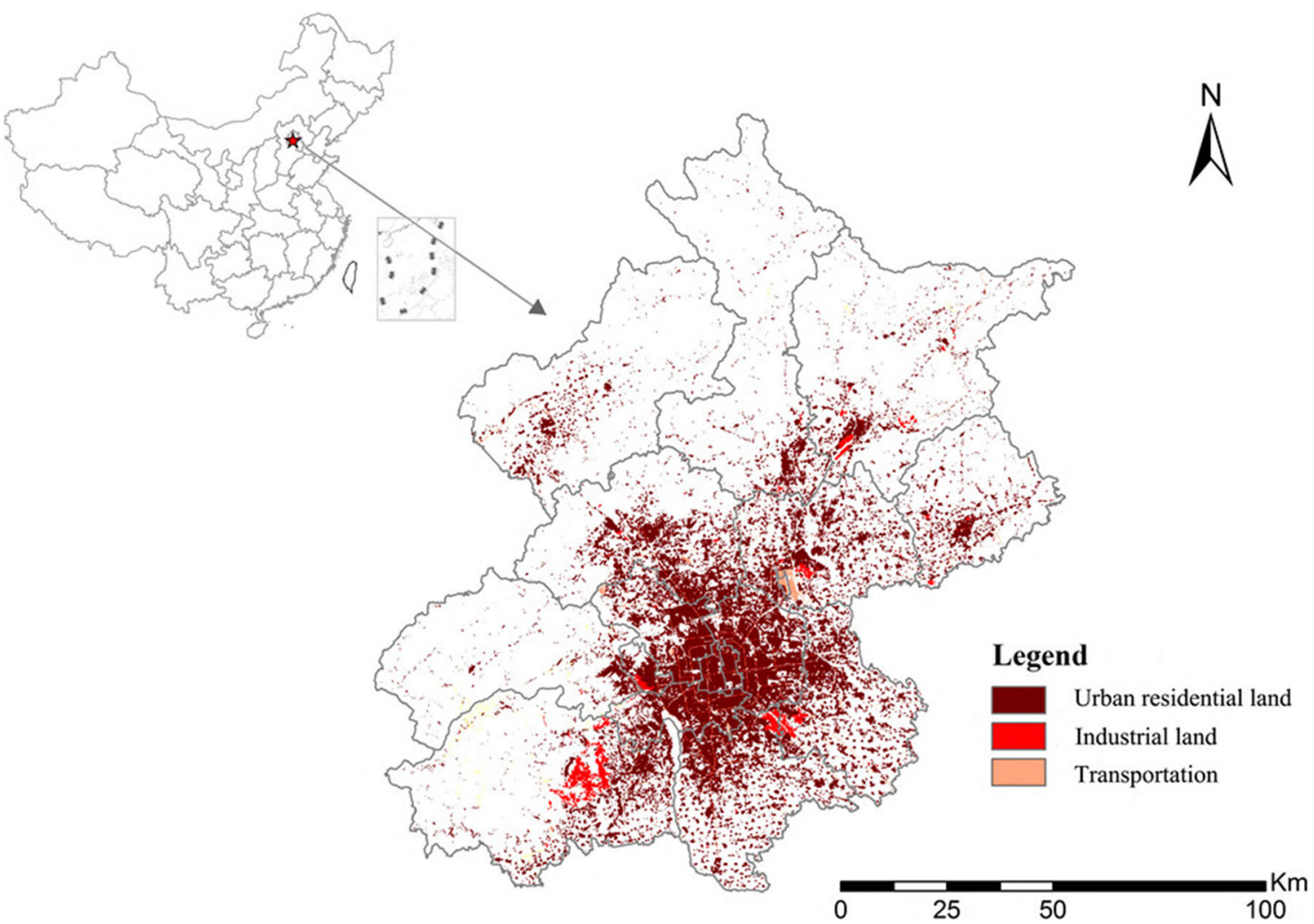

Fig. 1 Map of Beijing, China showing areas of urban residential land, industrial land, and transportation

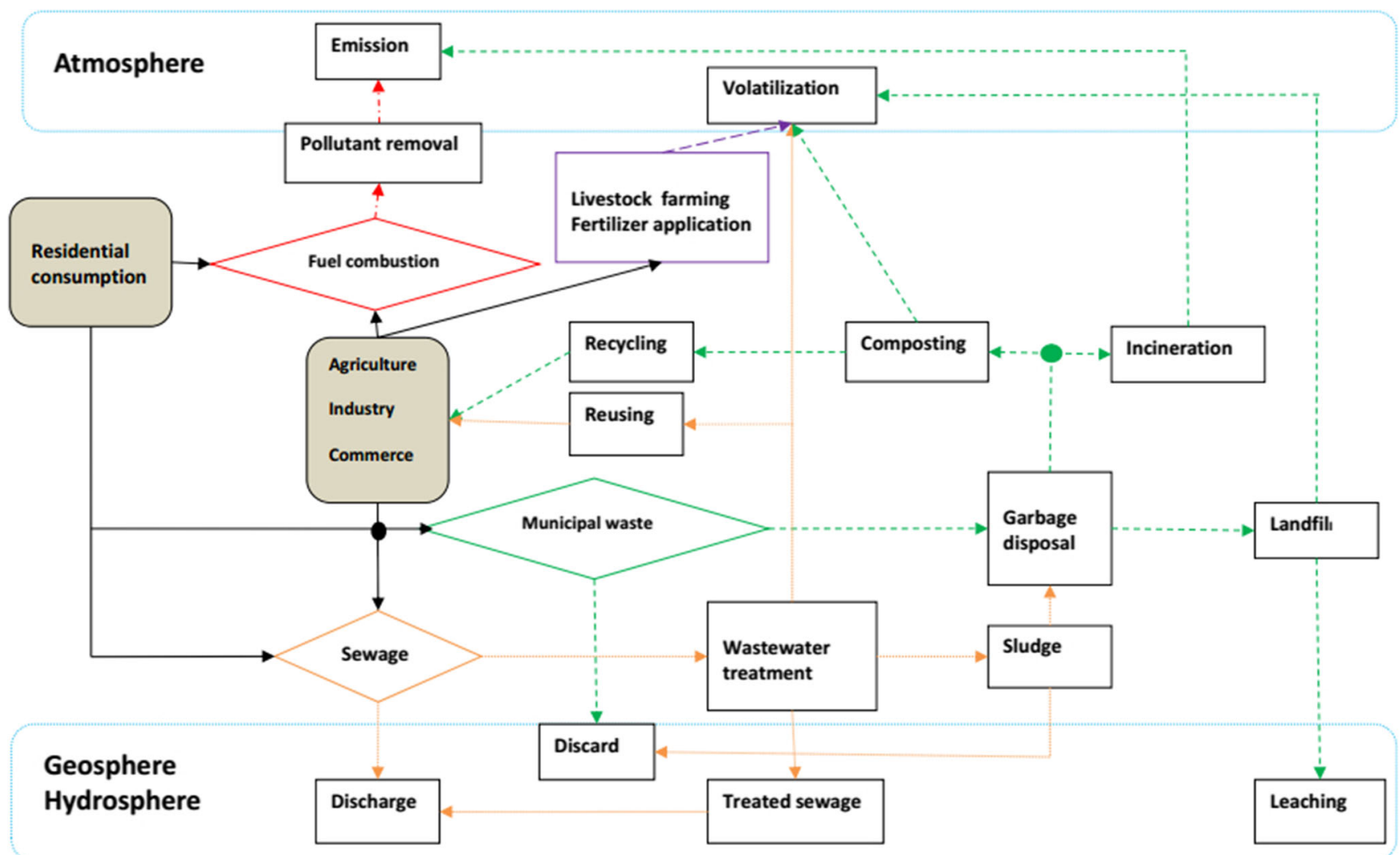

Fig. 2 Flow diagram showing emissions of forms of consumed N 


\section{Nr from fuel combustion}

The development of megacities, such as Beijing, with resource scarcity strongly relies on the "exotic" fossil fuels mainly raw coal, coke, crude oil, kerosene, diesel, and natural gas. Through the combustion of these resources, the reactive $\mathrm{N}$ fixed in the fuel is emitted directly into the atmosphere in the form of oxynitride (mainly $\mathrm{NO}_{2}$ ) since the fuel combustion sector was a less critical source of $\mathrm{N}_{2} \mathrm{O}$ emissions in China (Reis et al. 2009), contributing to air pollution and the greenhouse effect. Generally, both historical and future emissions are derived from fuel consumption, emission factors, and assumptions on the removal efficiency by the penetration of control technologies (Zhao et al. 2013). Based on the resource consumption structure of Beijing, the sectors related to fuel combustion generally include petrochemical refining, electricity production, transportation, commercial activity, residential consumption, agricultural, and industrial and constructional activities. The emission factors for each fuel in the sectors were obtained from Gu et al. (2012b) and Zhou et al. (2014a) (Table 1), which are the most widely applied Nr emission factor datasets in China (Gu et al. 2012a, 2013b, 2015). Given that the integrated statistics of $\mathrm{Nr}$ removal rates (i.e., the percentages of $\mathrm{Nr}$ emissions reduced by pollution control measures) in the sectors mentioned above are unavailable in Beijing, we set the annual $\mathrm{Nr}$ removal rates based on the $\mathrm{NO}_{\mathrm{x}}$ removal efficiency of sectors in China concluded by Hao et al. (2002) and Shi et al. (2014). Here, we calculated the Nr emissions by the bottom-up emission inventory approach using Eq. 1:

$Q_{\mathrm{ij}}^{\mathrm{N}}=\sum_{i=1}^{n} \sum_{j=1}^{n} C_{\mathrm{ij}} \cdot E_{\mathrm{ij}} \cdot\left(1-P_{\mathrm{D}}\right)$,

where $Q^{\mathrm{N}}$ was the amount of $\mathrm{Nr}$ emitted by the fuel combustion with $i$ and $j$ representing the fossil fuels and sociometric sectors in Beijing, respectively. $C_{\mathrm{ij}}$ was the total amount of $i$ fuel consumed in the $j$ sector, and $E_{\mathrm{ij}}$ was the emission factor of $i$ fuel in the $j$ sector. $P_{\mathrm{D}}$ denoted time series of $\mathrm{Nr}$ removal rates and assumed to be $3 \%$ in $2000-2005$, $4.5 \%$ in 2005 2010 , and $9 \%$ in 2010-2012, based on $\mathrm{NO}_{\mathrm{x}}$ removal efficiency (presuming $\mathrm{NO}_{2}$ removal rates due to instability of $\mathrm{NO}$ ) as $10 \%$ in $2000-2005,15 \%$ in 2005-2010, and $30 \%$ in 2010 2012.

\section{$\mathrm{Nr}$ from wastewater treatment}

Beijing relies on water sources from other regions because it has limited water supply of its own. For example, the national "South-to-North Water Diversion" project, which took nearly 13 years to complete, pipes water from Southern China to mitigate the water shortages in Beijing and Northern China. Widespread wastewater treatment facilities have a key role in alleviating the increase in $\mathrm{Nr}$ discharge into surface water. Although the number of such treatment plants in Beijing is increasing, from 4 in 2000 to 24 in 2012, with average sewage treatment rates as high as $80 \%$, the increased facilities are unable to treat all the wastewater from the city, which results in the discharge of raw and even treated sewage directly into the rivers. The direct and indirect discharge of sewage are assumed to be the main sources of dissolved $\mathrm{Nr}$ release and significantly contribute to the $\mathrm{N}$ pollution of urban rivers in Beijing (Gu et al. 2009; Ren et al. 2014).

As an emerging $\mathrm{N}$ source, wastewater treatment in urban ecosystems not only emits dissolved $\mathrm{Nr}$ to the environment but also results in the emission of gaseous nitrogen oxides (mainly nitrous oxide $\left(\mathrm{N}_{2} \mathrm{O}\right)$ ) and sludge, in which $\mathrm{Nr}$ are embedded. The former contributes to the greenhouse effect and the latter to secondary pollution if the sludge is not properly treated. The $\mathrm{Nr}$ emission from wastewater treatment in Beijing was estimated using Eq. 2:

$L \mathrm{~S}=L \mathrm{~g}+L \mathrm{sl}(1-P \mathrm{DSL})+L \mathrm{w}+M \cdot C \mathrm{TNp}(1-P \mathrm{D})$,

where $L_{\mathrm{S}}$ was total amount of $\mathrm{Nr}$ output from wastewater treatment and $M$ was the annual amount of sewage produced by Beijing; $L_{\mathrm{g}}, L_{\mathrm{sl}}$, and $L_{\mathrm{w}}$ presented the Nr outputs embedded in $\mathrm{N}_{2} \mathrm{O}$, sludge, and treated wastewater, respectively. $P_{\mathrm{D}}$ was
Table $1 \mathrm{Nr}$ emission factors of fossil fuel combustion in different sociometric sectors $\left(\mathrm{g} \mathrm{N} \mathrm{kg}^{-1}\right)$

\begin{tabular}{llllllll}
\hline Sectors & Coal & Coke & Crude oil & Gasoline & Kerosene & Diesel & Natural gas $^{\mathrm{a}}$ \\
\hline Commerce & 1.1 & 1.4 & 0.9 & 5.1 & 1.4 & 0.8 & 0.4 \\
Refining & 0.3 & - & 0.1 & - & - & - & - \\
Construction & 2.3 & 2.7 & - & 5.1 & 2.3 & 2.9 & 0.6 \\
Electricity & 3.0 & - & 2.2 & 5.1 & 6.5 & 8.3 & 1.2 \\
Agriculture & 3.0 & - & - & 6.7 & - & 9.4 & - \\
Industry & 2.3 & 2.7 & 1.5 & 5.1 & 2.3 & 2.9 & 0.6 \\
Residents & 0.6 & 0.7 & 0.5 & 5.1 & 0.8 & 1.0 & 0.4 \\
Transportation & 2.3 & 2.7 & 1.5 & 7.4 & 8.3 & 16.5 & 0.6 \\
\hline
\end{tabular}

${ }^{\mathrm{a}}$ Unit of emission: $\mathrm{g} \mathrm{N} \mathrm{m}^{-3}$ 
the sewage treatment rate, whereas $P_{\mathrm{DSL}}$ was the sludge disposal rate. $C_{\mathrm{TNp}}$ was $\mathrm{N}$ concentrations of sewage.

The annual production of $\mathrm{N}_{2} \mathrm{O}$ can be calculated on the basis of the total $\mathrm{N}$ removed during treatment (Yan et al. 2014) (Eq. 3), and the production of sludge can be estimated based on the production of mixed liquor volatile suspended solids (MLVSS), with the average percentage of it in sludge being approximately $60 \%$ in Beijing (Yu and Wang 2003) (Eq. 4). Based on a survey conducted in 2008, the treatment rate of sludge in Beijing was $46.4 \%$, and the average $\mathrm{N}$ content of sludge was approximately $4.61 \%$ (Tan et al. 2011a, b). The treated sludge is proposed not to have a negative impact on the environment because its recycling has no adverse environmental effect; therefore, the $\mathrm{Nr}$ included in this sludge was not included in our calculations. According, the $L_{\mathrm{w}}$ was estimated by Eq. 5 .

$L \mathrm{~g}=M \cdot P \mathrm{D}(C \mathrm{TN} p-C \mathrm{TNf}) \cdot C \mathrm{~g} \cdot C \mathrm{gN}$,

where $C_{\mathrm{TNp}}$ and $C_{\mathrm{TNf}}$ were the annual total $\mathrm{N}$ concentrations of sewage before and after treatment, respectively, the values of which referred to the average daily values of 365 days in 2009 provided by Qinghe sewage treatment plant, one of the biggest sewage treatment plants in Beijing. $C_{\mathrm{g}}$ was the yield coefficient of $\mathrm{N}_{2} \mathrm{O}$, and $C_{\mathrm{gN}}$ was the $\mathrm{N}$ content of that yield.

$L \mathrm{sl}=M \cdot P \mathrm{D}(C \mathrm{BODp}-C \mathrm{BODf}) \cdot C \mathrm{VSS} \cdot C \mathrm{sl} \cdot C \mathrm{slN}$,

As above, $C_{\mathrm{BODp}}$ and $C_{\mathrm{BODf}}$ were the annual 5-day biochemical oxygen demand $\left(\mathrm{BOD}_{5}\right)$ concentrations of sewage before and after treatment, respectively, from the same source as for Eq. 3. $C_{\mathrm{VSS}}$ was the yield coefficient of MLVSS (generally half the amount of $\mathrm{BOD}_{5}$ removed during the processes of sewage treatment in Beijing) (Yu and Wang 2003), and $C_{\mathrm{sl}}$ was the yield coefficient of sludge with its $\mathrm{N}$ content being $C_{\mathrm{sIN}}$.

$L \mathrm{w}=M \cdot P \mathrm{D}(1-\mathrm{Pr}) \cdot C \mathrm{TNf}$,

where $P_{\mathrm{r}}$ was the percentage of treated sewage reuse, which increased from 23 to $61 \%$ during 2000-2012. The values related to the ratio of the amount of reclaimed water: The total wastewater sent for treatment, retrieved from the China statistical yearbook on the environment.

\section{$\mathrm{Nr}$ from municipal garbage disposal}

Municipal solid waste runs through the processes of production, consumption, and recycling, eventually being partly discharged into the environment as waste excretion (Kennedy et al. 2007). This has a close relationship with urban environment pollution, such as white pollution, eutrophication, and insanitation. The $\mathrm{Nr}$ embedded in municipal garbage in Chinese cities can easily contaminate the environment as a result of garbage discarding (Zhou et al. 2014b). In addition, some $\mathrm{Nr}$ will be gradually emitted to the environment during or after the disposal processes, including via emissions, volatilization, and leaching, resulting in the growth of potential urban $\mathrm{Nr}$ sources. Similar to wastewater treatment, Beijing has many advanced waste disposal facilities with municipal garbage disposal rates reaching $99.1 \%$ in 2012, which is higher than most cities in China (Beijing Statistics Bureau 2013). However, the $\mathrm{Nr}$ emissions after garbage disposal generally are ignored by inhabitants in most cases compared with those resulting from untreated garbage.

Based on the survey statistics in 2000 (Gao et al. 2000), the composition of municipal garbage in Beijing included organic waste, such as food waste, paper, fabric, and plastic, and inorganic waste, such as metal, glass, and ash. Given the lack of annual data relating to the composition of garbage following 2000, we assumed that the garbage composition remained the same until 2012; the $\mathrm{Nr}$ embedded in the garbage was calculated using the $\mathrm{N}$ content of the different waste materials, as detailed in Table 2 (Nie 2000; Wu et al. 2006; Gu et al. 2013b) (Eq. 6). Given that the $\mathrm{N}$ content of metal and glass are low and cannot be degraded naturally, the $\mathrm{Nr}$ from these was not included in our calculation.

$M \mathrm{~N}=(1-P \mathrm{D}) \cdot \sum_{i=1}^{n}(P \mathrm{i} \cdot M \cdot P \mathrm{~N})$,

where $M_{\mathrm{N}}$ represented the $\mathrm{N}$ content of untreated garbage, $P_{\mathrm{D}}$ represented the garbage disposal rates, and $M$ was the total amount of garbage. $P_{\mathrm{i}}$ represented the mass fraction of waste $i$ with $P_{\mathrm{N}}$ as the $\mathrm{N}$ content coefficient.

The disposal of municipal garbage in Beijing relied on sanitary landfill (94\%) with composting (4\%) and incineration (2\%) (Xiao et al. 2007). Therefore, the $\mathrm{Nr}$ from garbage treatment can be summarized using the $\mathrm{N}$ embedded in the nitrous oxide emissions caused by incineration and the gas volatilization from composting and landfilling, as well as by $\mathrm{N}$ loss from uncollected leaching from landfilling (Liu et al. 2001; Intergovernmental Panel on Climate Change 2006)

Table 2 The percentages and $\mathrm{N}$ content factors of municipal garbage

\begin{tabular}{lll}
\hline Garbage & Percentage (\%) & N content (\%) \\
\hline Food waste & 39 & 2.6 \\
Paper & 18.18 & 0.3 \\
Metal & 2.96 & $<0.1$ \\
Glass & 13.02 & $<0.1$ \\
Fabric & 3.56 & 10 \\
Plastic & 10.35 & 0.5 \\
Coal ash & 10.93 & 0.98 \\
Others & 2 & - \\
\hline
\end{tabular}


(Eq. 7). The Nr flows with recycling were regarded as being redistributed within the city and so were excluded from the output calculation. In addition, the annual data relating to the treatment rates of leaching in Beijing were lacked, and so, we assumed that all the leaching infiltrated the groundwater in the same year as the preliminary treatment of landfilling. Thus, the total $\mathrm{Nr}$ emissions from treated and untreated garbage were evaluated using Eq. 7:

$L \mathrm{~N}=\sum_{j=1}^{n}(P \mathrm{j} \cdot M \cdot P \mathrm{D} \cdot C \mathrm{~g} \cdot C \mathrm{gN})+M 1 \mathrm{~N} \cdot L 1+M \mathrm{~N}$,

where $L_{\mathrm{N}}$ denoted the total $\mathrm{Nr}$ emissions from treated and untreated garbage, $P_{\mathrm{j}}$ was the percentage of disposal approach $j, C_{\mathrm{g}}$ was the emission factor of nitrous oxide with $67 \mathrm{~g} \mathrm{~kg}^{-1}$ for incineration and $0.6 \mathrm{~g} \mathrm{~kg}^{-1}$ for volatilization, and $C_{\mathrm{gN}}$ was the $\mathrm{N}$ content of the former. $M_{1 \mathrm{~N}}$ was the $\mathrm{N}$ embedded in the garbage for landfilling, with $L_{1}$ representing the $\mathrm{N}$ loss factor by leaching $(16 \%)$.

\section{$\mathrm{Nr}$ from agricultural ammonia volatilization}

Ammonia nitrogen, as an important species of reactive nitrogen, is very crucial on secondary aerosol formation. The agricultural ammonia emissions from suburban contribute to China urban air pollutions especially the higher $\mathrm{PM}_{2.5}$ level in Beijing (Gu et al. 2014). Reis et al. (2009) found that livestock farming and synthetic fertilizer application in China were the major contributions (52\%) and (41\%) to total ammonia emissions by the end of last century (Reis et al. 2009). Given that suburban regions occupy most territories of Beijing megacity where agricultural activities occurs frequently, we estimated $\mathrm{Nr}$ emissions from agricultural ammonia volatilization from 2000 in this study by using Eq. 8:

$L \mathrm{~A}=V 1+V \mathrm{f}$,

where $L_{\mathrm{A}}$ represented the total $\mathrm{Nr}$ losing through agricultural ammonia volatilization. $V_{1}$ and $V_{\mathrm{f}}$ indicated the annual $\mathrm{Nr}$ volatilization from livestock farming and synthetic fertilizer application in Beijing, respectively.

The $\mathrm{Nr}$ emissions in terms of ammonia volatilization from livestock farming were estimated by multiplying the rearing amounts by emission factors for different types of livestock (Eq. 9). The livestock species in Beijing mainly included beef cattle, pig, sheep, rabbit, duck, chicken, and hen, and the $\mathrm{Nr}$ emission rates of these livestock were referred to the volatile coefficients concluded by Gu et al. (2015), which included $\mathrm{Nr}$ embedded in ammonia emissions from the storage, manure, and grazing during livestock rearing.

$V 1=\sum_{l=1}^{n}(Q 1 \cdot E \mathrm{l})$, where $Q_{1}$ denoted the rearing capita of livestock species $l$ by the end of year and $E_{1}$ represented the annual ammonia emissions factors for beef cattle $\left(18.6 \mathrm{~kg} \mathrm{~N}\right.$ capita $\left.^{-1}\right)$, pig $(2.33 \mathrm{~kg}$ $\mathrm{N}$ capita $\left.^{-1}\right)$, sheep $\left(4.18 \mathrm{~kg} \mathrm{~N}\right.$ capita $\left.^{-1}\right)$, duck $(0.25 \mathrm{~kg} \mathrm{~N}$ capita $\left.^{-1}\right)$, rabbit $\left(0.20 \mathrm{~kg} \mathrm{~N} \mathrm{capita}{ }^{-1}\right)$, chicken, and hen $\left(0.04 \mathrm{~kg} \mathrm{~N}\right.$ capita $\left.^{-1}\right)$.

Current agricultural productions in China are still dependent on intensive fertilizer use, and synthetic fertilizer application is one of the important sources of gaseous $\mathrm{Nr}$ emissions through ammonia volatilization. We estimated these $\mathrm{Nr}$ emissions in Beijing by multiplying the used fertilizers (nitrogenous fertilizer and compound fertilizer) by the emission factors using Eq. 10:

$V \mathrm{f}=(F \mathrm{~N}+Q \mathrm{C} \cdot P \mathrm{~N}) \cdot E \mathrm{f}$,

where $F_{\mathrm{N}}$ represented the annual net $\mathrm{N}$ amount embedded in nitrogenous fertilizer applied in agriculture and $Q_{\mathrm{C}}$ denoted the annual amount of compound fertilizer, they could be retrieved from the statistics by Ministry of Agriculture of China $(2000-2013) . P_{\mathrm{N}}$ was average nitrogen content $(15 \%)$ of compound fertilizer based on survey in Beijing (Irie et al. 2014), and $E_{\mathrm{f}}$ was the loss rate (16\%) of $\mathrm{N}$ applied as inorganic $\mathrm{N}$ in Beijing's farmland through ammonia volatilization (Gu et al. 2015)

\section{$\mathrm{Nr}$ from different sources}

Exploring the characteristics of $\mathrm{Nr}$ emissions from different sources can demonstrate the main sources driving $\mathrm{Nr}$ outputs in Beijing. Recently, as Liu et al. (2015) suggested, the impact of urbanization on $\mathrm{N}$ flow was reflected in the changes in urban lifestyles and urban production styles. Thus, we categorized the total $\mathrm{Nr}$ outputs into two groups based on the emission source. The first was residential emissions $\left(N r_{\mathrm{r}}\right)$, which included emissions from fossil fuel combustion by inhabitants, sanitary sewage treatment, and municipal garbage disposal. The second was industrial emissions $\left(N r_{\mathrm{p}}\right)$ caused by primary, secondary, and tertiary industries, including direct emissions from fossil fuel combustion by commodities and services production, as well as indirect emissions from agricultural activities and industrial sewage treatment. Given that the rainy season in Beijing is short with little rainfall and that the limited agricultural wastewater is not collected for treatment in Beijing, the wastewater mentioned above mainly comprised sanitary and industrial sewages, and their percentages were based on the statistics from China statistics yearbooks and China environmental statistics yearbooks. Given the lack of data relating to industrial waste residue and the fact that they generally were treated in a different way to municipal garbage, the emissions from the disposal of these wastes were not included here, unavoidably causing us to underestimate the total industrial emissions. We evaluated the $\mathrm{Nr}$ 
emissions from these two sources using Eqs. 11 and 12, respectively:

$\mathrm{Er}=\frac{N r \mathrm{r}}{P}$,

$E \mathrm{p}=\frac{N r \mathrm{p}}{G}$,

where $E_{\mathrm{r}}$ and $E_{\mathrm{p}}$ denoted the residential and industrial $\mathrm{Nr}$ output intensity, respectively, which could reflect the ratio between $\mathrm{Nr}$ output and economic or human welfare output (Cui et al. 2013). The lower these indicators are, the lower the environmental costs for urbanization. $P$ was the annual residential population, and $G$ was the gross domestic product (GDP) of Beijing in the same year. Generally, $E_{\mathrm{r}}$ represented the amount of $\mathrm{Nr}$ emitted to the environment resulting from the feeding of one inhabitant in Beijing; similarly, $E_{\mathrm{p}}$ represented the amount of $\mathrm{Nr}$ discharged to the environment to produce the commodities and services with the value of 100 million RMB.

\section{Evaluating $\mathrm{Nr}$ removal efficiency}

Given that the development of an urban ecosystem consumes $\mathrm{N}$ and results in $\mathrm{Nr}$ emissions to the environment, it is useful to evaluate the $\mathrm{Nr}$ removal efficiency of that urban ecosystem from the perspective of urban metabolism, especially in megacities with rapid urbanization. In this study, data envelopment analysis (DEA), which was widely applied in economic analysis, was used to measure the $\mathrm{Nr}$ removal efficiency of Beijing. This model is a linear programming-based technique for evaluating the relative efficiency of a decision-making unit (DMU) with other DMUs with the same resource consumption (material input) to produce the same output. It recently was applied as a method for the eco-efficiency assessment of urban material metabolism in China, with $\mathrm{N}$ discharge being one of the undesirable outputs (Zhang et al. 2008; Liu et al. 2010). To focus on the removal efficiency of Beijing from 2000 to 2012, the application of DEA developed by Coelli (1996) was conducted as suggested by Liu et al. (2010), and the evaluation accounting for variable returns to scale (VRS) situations was carried out using DEAP version 2.1 program. By considering DMUs with time series data (years) and assuming that the environmental technology for pollutant removal did not vary across years to enable a comparison among DMUs based on the extent to which inputs are used efficiently in the output production, the DEA model can be used with time series data. For each DMU for a specific year, its inputs and outputs are considered in the model. For the purpose of this study, $\mathrm{Nr}$ discharge was recognized as the only output item; the input items included the governmental investment for pollution control, total amount of water consumption, and the land exploration for urbanization (Table 3).
Energy consumption was not considered to avoid repetition because of the $\mathrm{Nr}$ output calculation based on the amount of energy consumption. During the evaluation, the undesirable $\mathrm{Nr}$ outputs were treated as normal outputs after taking their reciprocals to match the model application (Lovell et al. 1995). The output slack will occur only if it is possible to increase the amount of output when keeping the same input (Coelli 1996). Therefore, the DMU could be assumed to be efficient (value $=1$ ) if the output could not be increased anymore on the premise of maximum input; otherwise, the DMU remains inefficient (value $<1$ ) with output slack. In the current study, this means that, in an efficient year, the $\mathrm{Nr}$ output could not be reduced further based on the realistic input of money, water, and land. All the input item from 2000 to 2012 for the model were mainly collected from China City Statistical Yearbooks, China Statistical Yearbooks, Beijing Statistical Yearbooks, and China Environmental Statistical Yearbooks.

\section{Results and discussions}

\section{Beijing Nr emissions with pollution control}

Using the equations detailed above, we determined the temporal changes in $\mathrm{Nr}$ emissions from fuel combustion, wastewater treatment, municipal garbage disposal, and agricultural ammonia volatilization from 2000 to 2012 in Beijing. As to $\mathrm{Nr}$ emissions by fuel combustion, we found that the emission amounts resulting from coke and crude oil consumptions reduced over this time period. As the biggest contributor, emissions by coal combustion fluctuated over the period and dropped to $42.3 \times 10^{3} \mathrm{t} \mathrm{N}$ in 2012, peaking at $60.3 \times 10^{3} \mathrm{t} \mathrm{N}$; the obvious reduction of these emissions may have resulted from the efforts to upgrade the energy and industrial structure especially during the 11th 5-year plan period (2005-2010) in China; by contrast, emissions from secondary and clean energy combustion, including gasoline, kerosene, diesel, and natural gas, grew gradually (Fig. 3a). The consumption of coal, gasoline, and diesel was assumed to be the main source for burning $\mathrm{Nr}$ output by Beijing, and the secondary energy source, such as gasoline and diesel, mainly was used in the transportation sector. Thus, our results indicated that a boom in transportation had a key role in increasing regional air pollution in Beijing, as predicted by a previous study ( $\mathrm{Li}$ et al. 2003). Generally, the $\mathrm{Nr}$ emissions from fuel combustion increased gradually from 2000 , peaking at $119.7 \times 10^{3} \mathrm{t} \mathrm{N}$ in 2007 and then decreased slightly to the bottom $108.9 \times 10^{3} \mathrm{t}$ $\mathrm{N}$ in 2011, which still increased by $39 \%$ compared with the level in 2000, with average $\mathrm{Nr}$ emissions of approximately $102.6 \times 10^{3} \mathrm{t} \mathrm{N}$ during the study period. Compared with the results of provincial $\mathrm{NO}_{\mathrm{x}}$ (presuming $\mathrm{NO}_{2}$ ) emissions conducted by Zhao et al. (2013), our $\mathrm{Nr}$ emission estimations $\left(103.2 \times 10^{3} \mathrm{t} \mathrm{N}\right.$ in 2005 and $112.6 \times 10^{3} \mathrm{t} \mathrm{N}$ in 2010) were 
Table 3 Summary of input indicators

\begin{tabular}{lllcll}
\hline Indicators & Units & Mean & Std. deviation & Min & Max \\
\hline Governmental investment & $10,000 \mathrm{RMB}$ & $53,795.92$ & $30,364.65$ & 10,512 & 99,046 \\
Water consumption & $10,000 \mathrm{t}$ & 357,000 & $15,247.95$ & 343,000 & 389,000 \\
Land exploration & $100 \mathrm{ha}$ & 73.62 & 94.58 & 0 & 292 \\
\hline
\end{tabular}

lower than his estimations around $108.9 \times 10^{3} \mathrm{t} \mathrm{N}$ in 2005 and $144 \times 10^{3} \mathrm{t} \mathrm{N}$ in 2010 in Beijing, approximately resulting from our applications of $\mathrm{Nr}$ removal rates covering all the sectors mentioned above while removal efficiency in his study focusing on the industrial sector and power plants.

$\mathrm{Nr}$ emissions from wastewater treatment declined from 2003 onwards and remained stable between 2008 and 2012, with the percentage of $\mathrm{Nr}$ embedded in untreated sewage dropping sharply (Fig. 3b). This indicated that Beijing effectively reduced $\mathrm{Nr}$ emissions originating from wastewater by increasing the sewage treatment rate. The average $\mathrm{Nr}$ emission from 2000 to 2012 was $35.1 \times 10^{3} \mathrm{t} \mathrm{N}$ and declined by $29.9 \times 10^{3}$ t $\mathrm{N}$ during the last 5 years of the study period, highlighting the positive impacts of wastewater treatment on the Beijing environment. However, because sludge could remove more $\mathrm{Nr}$ from sewage with the improvement in treatment technology, the growth of sludge production might, in turn, become a potential $\mathrm{Nr}$ source.

$\mathrm{Nr}$ emissions caused by the discard of untreated municipal garbage decreased rapidly, especially between 2000 and 2001, with a reduction of more than $50 \%$ (Fig. 3c). The improvement of municipal garbage treatment rates supported by the construction of more treatment facilities and advanced technologies is likely to have prevented the direct channeling of $\mathrm{Nr}$ emissions to the environment. However, there was a rising trend in $\mathrm{Nr}$ emissions via gaseous and liquid carriers following disposal over the study period. The amount of Nr loss by landfill leaching rose dramatically, resulting in it becoming the fastest growing source of nitrate contamination in groundwater, secondary only to farmland leaching (Gu et al. 2013a). Similarly, the amount of gaseous Nr emissions increased gradually from 2000 to 2012 . In particular, the exhaust gas emissions resulting from incineration significantly contributed to these $\mathrm{Nr}$ emissions, despite it having the lowest percentage (2\%) for garbage disposal in Beijing. In summation, the amount of $\mathrm{Nr}$ emissions from municipal garbage disposal dropped from 2000 and returned to a high level in 2006 and was maintained until 2012, with the overall average of $22.2 \times 10^{3} \mathrm{t} \mathrm{N}$ and an average of $24.8 \times 10^{3} \mathrm{t} \mathrm{N}$ between 2006 and 2012. These results indicate that the process of garbage disposal is fast becoming a potential source of $\mathrm{N}$ pollution in Beijing.

Gaseous Nr emissions resulting from livestock farming and fertilizer application exhibited rapid downtrend between 2003
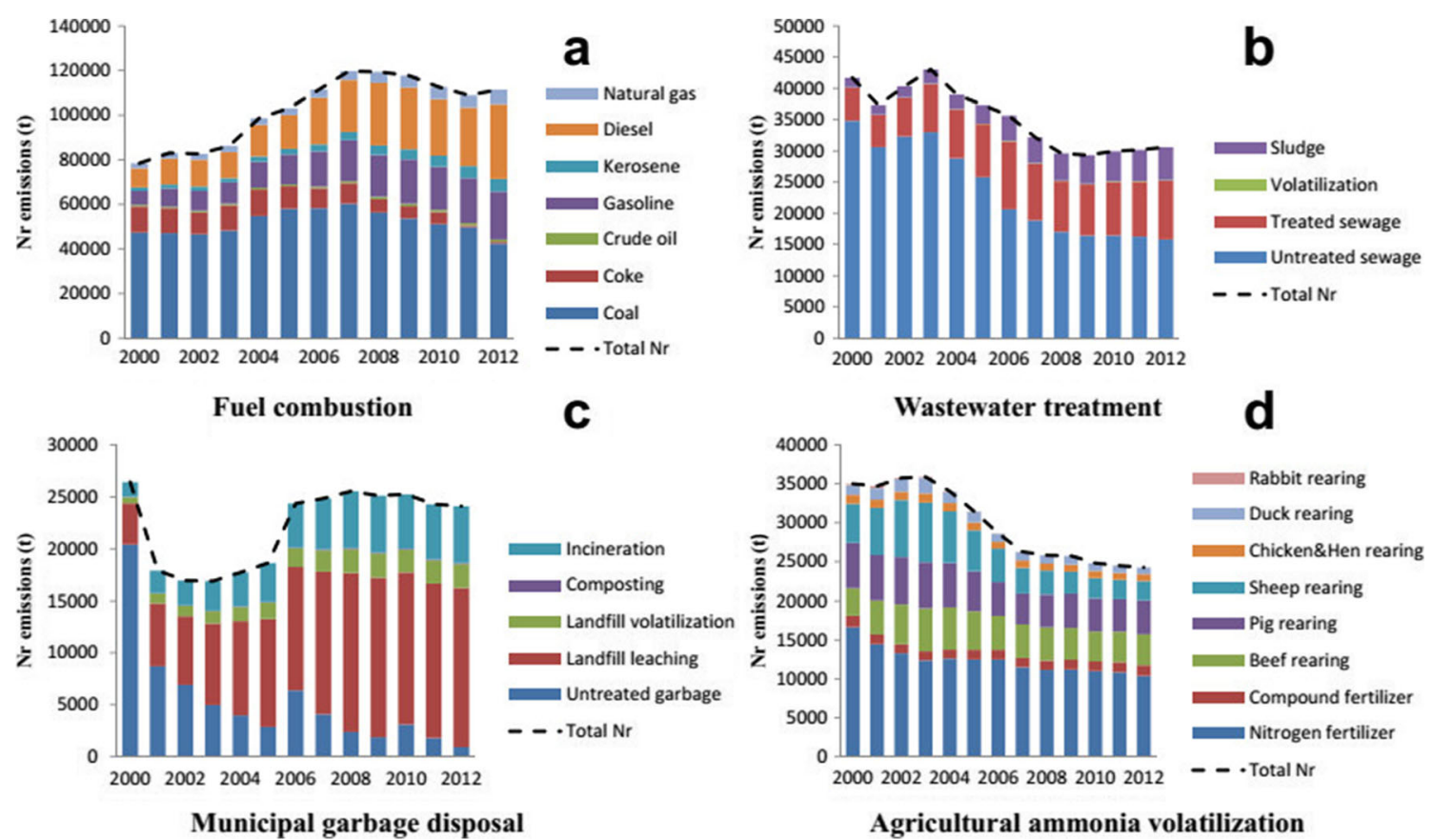

Agricultural ammonia volatilization

Fig. 3 Graph showing the relationship between $\mathrm{Nr}$ emissions and fuel combustion (a), wastewater treatment (b), municipal garbage disposal (c), and agricultural ammonia volatilization (d) 
and 2007 and kept decreasing slightly until 2012 with overall annual $\mathrm{Nr}$ emissions of $29.8 \times 10^{3} \mathrm{t} \mathrm{N}$ (Fig. 3d). Nitrogenous fertilizer was the biggest contributor to the nitrogen load, and the $\mathrm{Nr}$ from chemical fertilizers declined gradually from $18.1 \times 10^{3}$ to $11.8 \times 10^{3} \mathrm{t} \mathrm{N}$ achieving around $35 \%$ reduction in 12 years, which was consistent with the finding in other Chinese megacity Shanghai that the Nr release resulting from chemical fertilizer decreased with increasing urbanization in the same period (Liu et al. 2015). Meanwhile, the $\mathrm{Nr}$ emissions from livestock farming presented increasing until 2003 with two bigger contributors of pig and sheep farming, then decreased from $22.4 \times 10^{3}$ to $12.5 \times 10^{3} \mathrm{t} \mathrm{N}$ by 2012 , which was mainly driven by significant scale-down of sheep farming with $51.6 \%$ reduction in rearing capita. Although beef cattle per capita produces more $\mathrm{Nr}$ emissions than sheep and pig during rearing, the scale of sheep farming was the main factor driving the trend of livestock $\mathrm{Nr}$ emissions in Beijing during study time while the breeding number of beef cattle and pig remained stable since 2006 . What should be noted that the amount of livestock $\mathrm{Nr}$ emissions exceeded those from chemical fertilizers since 2001, this indicated that livestock farming was the main source responsible for nonpoint $\mathrm{Nr}$ releasing in terms of agricultural ammonia volatilization. The overall decrease of these $\mathrm{Nr}$ emissions was due to urbanization resulting in reductions in farmland and local agricultural production in Beijing undergoing primary industrial transformation.

In conclusion, the total $\mathrm{Nr}$ emissions presented slightly increasing from 0.18 to $0.19 \mathrm{Tg} \mathrm{N}\left(\times 10^{6} \mathrm{t} \mathrm{N}\right)$ during 2000 2012, peaking at around $0.20 \mathrm{Tg} \mathrm{N}$ in 2007 (Fig. 4). Since 2007, the Nr load of the Beijing turned to be reduced gradually toward relatively stable, because of the reduction in fuel combustion emissions, which annually represented the largest percentage (43-60\%) of total $\mathrm{Nr}$ output, with $\mathrm{Nr}$ emissions caused by wastewater treatment coming second. The average $\mathrm{Nr}$ emissions reached $0.19 \mathrm{Tg} \mathrm{N}$ during the study period, with an average $N r_{\mathrm{r}}$ of $0.06 \mathrm{Tg} \mathrm{N}$ and $N r_{\mathrm{p}}$ of $0.11 \mathrm{Tg} \mathrm{N}$ (Fig. 4), indicating that the domestic production was still the main source of $\mathrm{N}$ pollution in Beijing, in which the percentage of industrial land covering was lower. The treatment of residential waste (sewage and municipal garbage) resulted in more than $83 \% N r_{\text {r }}$ all the way, whereas fuel combustion caused approximately $72 \%$ annual $N r_{\text {p }}$ along with the contribution of agricultural ammonia volatilization decreasing. Meanwhile, $E_{\mathrm{r}}$ showed a decreasing stepwise trend, with an average $3.87 \mathrm{~kg}$ per inhabitant; its value in 2012 had declined by $38 \%$ compared with that in 2000 . Similarly, $E_{\mathrm{p}}$ declined sharply from 33.90 to $5.59 \mathrm{t}$ per commodities and services production, with a value of 100 million RMB in 2012, having reduced by $83 \%$ over the 12 -year study period, with an average $E_{\mathrm{p}}$ of $16.74 \mathrm{t}$ (Fig. 5).

These results show that the Nr output intensity of both sources in Beijing had weakened over the study period, with more significant changes in industrial $\mathrm{Nr}$ output intensity. This suggests that $\mathrm{N}$ consumption in Beijing had become more efficient, with fewer negative impacts on the environment. Pearson correlations of the Nr output intensity and urbanization rates were -0.805 for $E_{\mathrm{r}}$ and -0.963 for $E_{\mathrm{p}}$, which were both significant at the 0.01 level (two-tailed). From 2000 to 2012, the environmental costs of inhabitants in terms of their livelihood per inhabitant and domestic production per unit both were reduced, highlighting the fact that Beijing had made efforts to transfer from a "high $\mathrm{N}$ cost" role into the new "low $\mathrm{N}$ cost" model especially for hosting the Olympics Game in 2008, despite rapid urbanization having occurred since 2004.

\section{$\mathrm{Nr}$ removal efficiency in Beijing}

According to our results, the removal efficiency of $\mathrm{Nr}$ emissions of Beijing fluctuated over the study period (Table 4). There were eight efficient years and five inefficient years from 2000 to 2012. The average value of the removal efficiency was 0.993 , reaching its lowest point (0.965) in 2003. There were 4 years (2007-2009, and 2012) that had output slack. This shows that Beijing could increase the amount of output and still keep the same input. For this study, this means that Beijing is capable of reducing its $\mathrm{Nr}$ emissions further based on its current natural and financial resource consumption in an inefficient year; the targeted $\mathrm{Nr}$ emissions simulated by the model to achieve $\mathrm{Nr}$ removal efficient for the years $2007,2008,2009$, and 2012, respectively, were $199.72 \times 10^{3}, 194.21 \times 10^{3}, 191.61 \times 10^{3}$, and $188.75 \times 10^{3} \mathrm{t} \mathrm{N}$, less than original ones $\left(203.02 \times 10^{3}\right.$, $200.36 \times 10^{3}, 197.85 \times 10^{3}$, and $\left.190.37 \times 10^{3} \mathrm{t} \mathrm{N}\right)$. Similarly, the environmental measures in Beijing had achieved the maximum $\mathrm{Nr}$ reduction in eight efficient years with no output slack. Thus, $\mathrm{Nr}$ removal efficiency could be an instrument for sustainability analysis that indicates how efficient $\mathrm{Nr}$ removal is with regard to environment protection. Given the higher percentage of efficient years, Beijing tried best to reduce its $\mathrm{Nr}$ emissions as much as it should have over study period.

Our study does have some limitations. Owing to the lack of annual statistic data in some sectors, several coefficients from these sectors for total $\mathrm{Nr}$ emissions calculation from 2000 to 2012 were based on the available data for 1 year during the study period, which leads to a degree of uncertainty in terms of our final results. Furthermore, some parameters used in this calculation were retrieved from the literature, which might also introduce potential uncertainties. For future research, more in-depth datamining research is needed to improve the accuracy of these results. Moreover, we assumed that the environmental technology for $\mathrm{Nr}$ removal in Beijing did not vary significantly between 2000 and 2012 while applying the DEA model, which would lead to bias in evaluation 
Fig. 4 Total $\mathrm{Nr}$ emissions of Beijing comprising agricultural ammonia volatilization, wastewater treatment, total $\mathrm{Nr}$, garbage disposal, and fuel combustion during the period 2000-2012

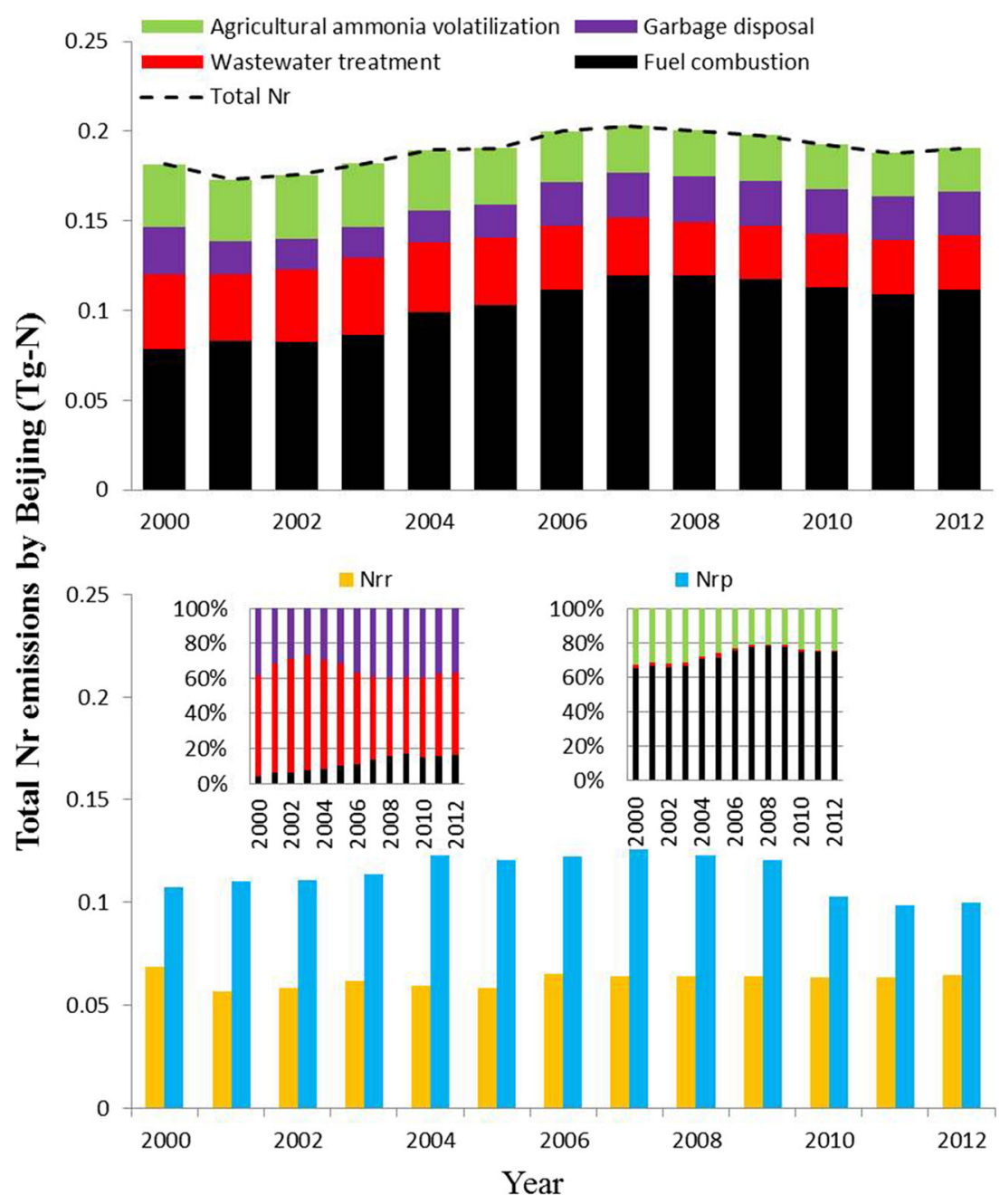

results of annual $\mathrm{Nr}$ removal efficiency. In reality, it is likely that technology improved gradually over the study period. The further refinements in the model extensions coupling with weight factors setting for DMUs might contribute to overcome this limitation.

\section{Further environmental measures for $\mathrm{Nr}$ removal based} on $\mathbf{N}$ offset

These results provide suggestions for further reducing local $\mathrm{Nr}$ emissions in Beijing. The countermeasures of $\mathrm{N}$ offset could
Fig. 5 Difference between industrial Nr output intensity from residential output intensity from year 2000 to 2012




Table 4 Removal efficiency of Beijing from 2000 to 2012

\begin{tabular}{lll}
\hline Year & Efficiency from VRS & Output slack \\
\hline 2000 & 1 & 0 \\
2001 & 1 & 0 \\
2002 & 1 & 0 \\
2003 & $0.965^{\mathrm{a}}$ & 0 \\
2004 & 1 & 0 \\
2005 & 1 & 0 \\
2006 & 1 & 0 \\
2007 & 0.986 & 0.077 \\
2008 & 0.982 & 0.159 \\
2009 & 0.986 & 0.169 \\
2010 & 1 & 0 \\
2011 & 1 & 0 \\
2012 & 0.987 & 0.048 \\
\hline
\end{tabular}

${ }^{a}$ The Nr removal inefficiency in 2003 might have resulted from input slack, in that the amount of input used could be reduced with the same output production

be developed to heighten $\mathrm{Nr}$ removal efficiency to avoid inefficient $\mathrm{Nr}$ removal, resulting in the overall reduction of $\mathrm{Nr}$ emissions. The concept of $\mathrm{N}$ offset is similar to the "N neutrality" concept defined by Leip et al. (2014) in that the purchase of $\mathrm{N}$ offsets compensates for residual $\mathrm{Nr}$ releases after removal. In this case, $\mathrm{N}$ offset could be purchased by government to neutralize the excess $\mathrm{Nr}$ emissions in a previous inefficient year with output slack by supporting low $\mathrm{N}$-producing projects, thus encompassing a reduction of $\mathrm{Nr}$ release elsewhere in Beijing during a specific period. For example, cleaner energy promotion and low-nitrogen technology in the production of heavy industrial sectors could be encouraged by governmental subsidies to avoid substantial $\mathrm{Nr}$ loss resulting from fuel combustion after 2012, balancing the remaining $\mathrm{Nr}$ emissions to achieve efficient $\mathrm{Nr}$ removal in what would otherwise be an inefficient year such as year
2012. Consequently, Beijing government had to spend extra investment in preventing future $\mathrm{Nr}$ emissions to offset the excess emissions $\left(1.62 \times 10^{3} \mathrm{t} \mathrm{N}\right)$ after $\mathrm{Nr}$ removal in a previously inefficient year 2012 (Fig. 6). This measure would stimulate the government to achieve more efficient years since the costs of subsequent $\mathrm{N}$ offset were higher due to compensation project establishment. Thus, this $\mathrm{N}$ offset measure could help Beijing progress toward minimal $\mathrm{Nr}$ emissions despite increasing urbanization.

Based on the characteristics of $\mathrm{Nr}$ emissions in Beijing detailed in this study, we suggest the following new environmental measures to help reduce such emissions: (i) systematically estimate the amount of realistic $\mathrm{Nr}$ emissions in Beijing following pollution control, (ii) evaluate and record the annual $\mathrm{Nr}$ removal efficiency of the city, (iii) implement compensation projects toward $\mathrm{N}$ offset to reduce superfluous $\mathrm{Nr}$ emissions in years lacking efficient $\mathrm{Nr}$ removal, and (iv) build a "N-friendly society" in the city to move it from an "Nr source" stage to an "Nr neutrality" stage.

\section{Conclusions}

As the basis for mitigation strategy making, effective approaches for main emission source identification and emission estimation have been a necessity. This study estimated and quantified anthropogenic $\mathrm{Nr}$ emissions from the Beijing megacity and presented a first attempt to evaluate the $\mathrm{Nr}$ removal efficiency of a city based on actual emissions and pollutant control. Our results could help not only policymakers but also other stakeholders, including producers and residents, to optimize strategies to minimize urban $\mathrm{Nr}$ emissions and enable an $\mathrm{N}$-friendly way forward for urbanization.

Our results can be summarized as follows: (i) The total amount of $\mathrm{Nr}$ emissions to the environment by Beijing increased during 2000-2007 and then slightly decreased during
Fig. 6 Graph showing environmental measures for $\mathrm{Nr}$ removal

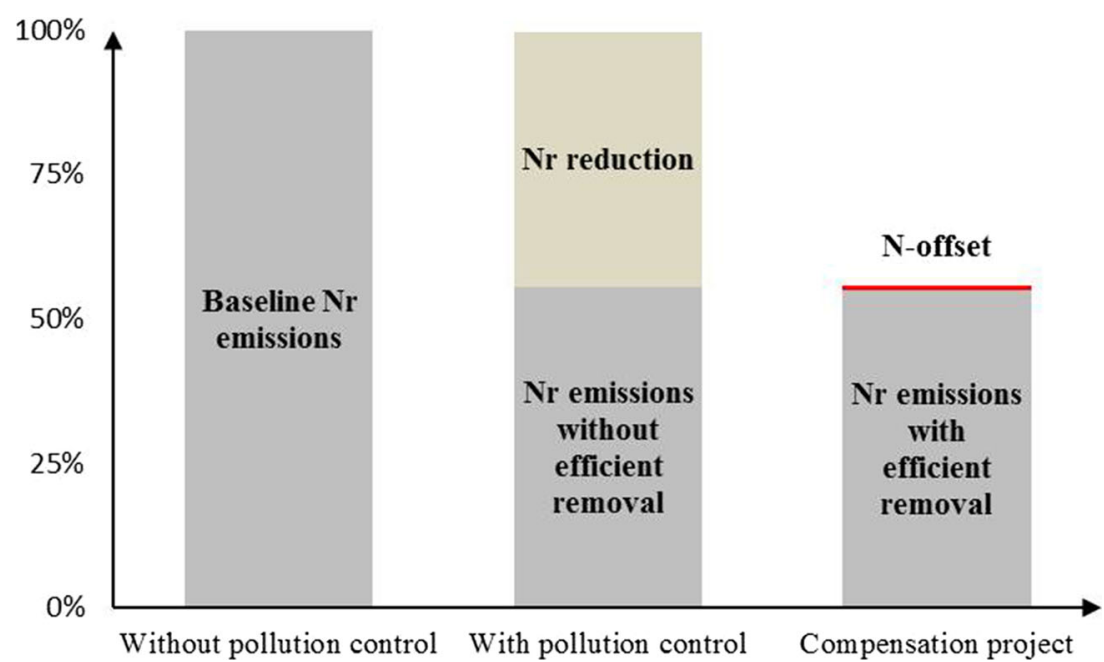


2008-2012 and were mainly due to fuel combustion; (ii) the Nr output intensity resulting from inhabitants' livelihoods and material production per unit decreased from 2000 to 2012; (iii) the environmental measures for $\mathrm{Nr}$ removal in Beijing were efficient in most years, indicating that progress on the mitigation of $\mathrm{Nr}$ load growth in this urban environment was significant especially during 2000-2006; and (iv) further measures based on $\mathrm{N}$ offset could provide a new approach to compensate for residual $\mathrm{Nr}$ emissions. Although this exploratory study focuses on the Beijing megacity as an example of an urban ecosystem undergoing rapid growth, the analysis framework for $\mathrm{Nr}$ estimations and removal efficiency evaluation method coupling with "N offset" concept might be suitable for use in case studies across other cities for exploring the relations between urbanization, environment protection, and sustainable development.

Acknowledgments This study was supported by the National Natural Science Foundation of China (Grant Number 71533005 and G031202). We are grateful to Dr. Xuesong Guo and Dr. Rong Qi from State Key Laboratory of Environmental Aquatic Chemistry for their constructive suggestions on the earlier version of the manuscript. Thanks to two anonymous reviews and editor for their help in improving a previous of this manuscript.

\section{Compliance with ethical standards}

Conflict of interest The authors declare that they have no conflict of interest.

\section{References}

Beijing Statistics Bureau (2013) Beijing Statistical Yearbook. China Statistics Press, Beijing (in Chinese)

Coelli TJ (1996) Centre for efficiency and productivity analysis (CEPA) working papers. http://www.une.edu.au/econometrics/cepa.htm. Accessed 3 April 2015

Cui S, Shi Y, Groffman PM, Schlesinger WH, Zhu Y (2013) Centennialscale analysis of the creation and fate of reactive nitrogen in China (1910-2010). Proc Natl Acad Sci U S A 110(6):2052-2057

Duh J, Shandas V, Chang H, George L (2008) Rates of urbanisation and the resilience of air and water quality. Sci Total Environ 400(1):238256

Galloway JN, Cowling EB (2002) Reactive nitrogen and the world: 200 year of change. Ambio 31(2):64-71

Galloway JN, Townsend AR, Erisman JW, Bekunda M, Cai Z, Freney JR, Martinelli LA, Seitzinger SP, Sutton MA (2008) Transformation of the nitrogen cycle: recent trends, questions, and potential solutions. Science 320(5878):889-892

Gao G, Dong Y, Jin H, Huang W (2000) Researches on countermeasures of municipal waste disposal and management. Urban Environment \& Urban Ecology 13(2):39-41 (in Chinese with English abstract)

Gu B, Chang J, Ge Y, Ge H, Yuan C, Peng C, Jiang H (2009) Anthropogenic modification of the nitrogen cycling within the Greater Hangzhou Area system, China. Ecol Appl 19(4):974-988
Gu B, Dong X, Peng C, Luo W, Chang J, Ge Y (2012a) The long-term impact of urbanization on nitrogen patterns and dynamics in Shanghai, China. Environ Pollut 171:30-37

Gu B, Ge Y, Ren Y, Xu B, Luo W, Jiang H, Gu B, Chang J (2012b) Atmospheric reactive nitrogen in China: sources, recent trends, and damage cost. Environ Sci Technol 46(17): 9420-9427

Gu B, Ge Y, Chang SX, Luo W, Chang J (2013a) Nitrate in groundwater of China: sources and driving forces. Global Environ Chang 23: $1112-1121$

Gu B, Leach AM, Ma L, Galloway JN, Chang SX, Ge Y, Chang J (2013b) Nitrogen footprint in China: food, energy, and nonfood goods. Environ Sci Technol 47(16): 9217-9224

Gu B, Sutton MA, Chang SX, Ge Y, Chang J (2014) Agricultural ammonia emissions contribute to China's urban air pollution. Front Ecol Environ 12(5):265-266

Gu B, Ju X, Chang J, Ge Y, Vitousek PM (2015) Integrated reactive nitrogen budgets and future trends in China. Proc Natl Acad Sci U S A 112(28):8792-8797

Han Y, Li X, Nan Z (2011) Net anthropogenic nitrogen accumulation in the Beijing metropolitan region. Environ Sci Pollut Res 3(18):485-496

Hao J, Tian H, Lu Y (2002) Emission inventories of $\mathrm{NO}_{\mathrm{x}}$ from Commercial Energy Consumption in China, 1995-1998. Environ Sci Technol 36:552-560

Intergovernmental Panel on Climate Change (2006) Guidelines for national greenhouse gas inventories. http://www.ipcc-nggip.iges.or.jp/ public/2006gl/vol5.html. Accessed 3 April 2015

Irie M, Jin Y, Li J, Yamaguchi T, Ushikubo A (2014) Estimation of nitrogen flow change in Beijing, China, for the years 1995, 2000, and 2004. J Mater Cycles Waste Manag 16(2):245-257

Kennedy C, Cuddihy J, Engel-Yan J (2007) The changing metabolism of cities. J Ind Ecol 11:43-59

Leip A, Leach A, Musinguzi P, Tumwesigye T, Olupot G, Tenywa JS, Mudiope J, Hutton O, Cordovil CMS, Bekunda M, Galloway J (2014) Nitrogen-neutrality: a step towards sustainability. Environ Res Lett 9(11):115001

Li W, Fu L, Hao J, Ma H, Li S, Hu W (2003) Emission inventory of 10 kinds of air pollutants for road traffic vehicles in China. Urban Environment \& Urban Ecology 16(2):36-38 (in Chinese with English abstract)

Lin T, Gibson V, Cui S, Yu C, Chen S, Ye Z, Zhu Y (2014) Managing urban nutrient biogeochemistry for sustainable urbanization. Environ Pollut 192:244-250

Liu J, Xu D, Zhao Y, Huang R, Zhou H, Zhang J (2001) Natural reduction of ammonia-N in leachate of large-scale landfill. Acta Sci Circumst 21(3):323-327 (in Chinese with English abstract)

Liu Y, Wang W, Li X, Zhang G (2010) Eco-efficiency of urban material metabolism: a case study in Xiamen, China. Int J Sust Dev World 17(2):142-148

Liu C, Wang Q, Zou C, Hayashi Y, Yasunari T (2015) Recent trends in nitrogen flows with urbanization in the Shanghai megacity and the effects on the water environment. Environ Sci Pollut R 22:34313440

Lovell CA, Pastor JT, Turner JA (1995) Measuring macroeconomic performance in the OECD: a comparison of European and nonEuropean countries. Eur J Oper Res 87(3):507-518

Ministry of Agriculture of China (2000-2013) China Agriculture Yearbook. China Statistics Press, Beijing (in Chinese)

National Bureau of Statistics of China (2000-2013a) China Statistical Yearbook. China Statistics Press, Beijing (in Chinese)

National Bureau of Statistics of China (2000-2013b) China Statistical Yearbook on Environment. China Statistics Press, Beijing (in Chinese)

National Bureau of Statistics of China (2000-2013c) China City Statistical Yearbook. China Statistics Press, Beijing (in Chinese)

Nie Y (2000) The Handbook for Engineering Technology of Waste Treatment. Chemical Industry Press, Beijing (in Chinese) 
Reis S, Pinder RW, Zhang M, Lijie G, Sutton MA (2009) Reactive nitrogen in atmospheric emission inventories. Atmos Chem Phys 9: $7657-7677$

Ren Y, Xu Z, Zhang X, Wang X, Sun X, Ballantine DJ, Wang S (2014) Nitrogen pollution and source identification of urban ecosystem surface water in Beijing. Front Environ Sci Eng 8(1):106-116

Shi Y, Cui S, Xu S, Lin J, Huang W (2014) Nitrogen oxide emission in energy consumption in China from a consumption-based perspective. Acta Sci Circumst 34(10):2684-2692 (in Chinese with English abstract)

Sun B, Shen R, Bouwman AF (2008) Surface N balances in agricultural crop production systems in China for the period 1980-2015. Pedosphere 18(3):304-315

Tan G, Li W, He C (2011a) Preliminary discussions on the sludge treatment and disposal technology in urban municipal sewage plants in Beijing. South to North Water Diversion and Water Science \& Technology 9(2): 105-109(in Chinese with English abstract)

Tan G, Li W, He C (2011b) Analysis of characteristics of sludge in Beijing wastewater treatment plant. Science \& Technology Information 7: 435-437(in Chinese with English abstract)

Wu D, Zheng B, Tang X, Wang M, Hu J, Li S, Wang B, Finkelman RB (2006) Contents and distribution of nitrogen in Chinese coals. Earth Environ 34(1):1-6 (in Chinese with English abstract)
Xiao Y, Bai X, Ouyang Z, Zheng H, Xing F (2007) The composition, trend and impact of urban solid waste in Beijing. Environ Monit Assess 135:21-30

Yan X, Lin L, Liu J (2014) Characteristics of greenhouse gas emission in three full-scale wastewater treatment processes. J Environ Sci 26(2): 256-263

Yu L, Wang H (2003) Discussion on surplus sludge calculation in activated sludge process. Water \& Wastewater Engineering 29(8):23-26 (in Chinese with English abstract)

Zhang B, Bi J, Fan Z, Yuan Z, Ge J (2008) Eco-efficiency analysis of industrial system in China: a data envelopment analysis approach. Ecol Econ 68(1-2):306-316

Zhao B, Wang SX, Liu H, Xu JY, Fu K, Klimont Z, Hao JM, He $\mathrm{KB}$, Cofala J, Amann M (2013) $\mathrm{NO}_{\mathrm{x}}$ emissions in China: historical trends and future perspectives. Atmos Chem Phys 13: 9869-9897

Zhou T, Wang Y, Wang F, Feng Y (2014a) Analysis of the nitrogen footprint of agriculture in Guangdong. China Environmental Science 34(9): 2430-2438(in Chinese with English abstract)

Zhou C, Xu W, Cao A (2014b) Urban ecological metabolism of municipal solid waste: a review. Acta Ecologica Sinica 34(1): 33-40(in Chinese with English abstract) 